plastic repair, but excludes the sphere of the neurosurgeon. Although a massive bibliography follows each chapter, and although a considerable pumber of introductory pages are devoted to embryology, the book is essentially the expression of the authors' personal views on the surgery and radiotherapy of the head and neck. The opinions which are advanced are doubly valuable in that they are the fruit of many years of direct experience and are expressed with the greatest clarity. The book is rendered the more readable by the avoidance of all but the most significant statistics and by the inclusion of a profusion of illustrations.

R.S.M.

\section{ENGLISH-GERMAN MEDICAL DICTIONARY}

By F. S. Schoenewald, M.D.Berlin. Pp. viii + 242. London: H. K. Lewis. 1951. 35 s.

A handy well-printed volume; perhaps not quite so useful as its German-English counterpart. The two are strongly recommended and easily used volumes.

\section{A HISTORY OF MEDICINE}

\section{Vol. I: Primitive and Archaic Medicine}

By Henry E. Sigerist, M.D., D.LitT., LL.D.,

DR.H.C. Pp. xxi +564 , with ro4 illustrations.

New York: Oxford University Press. (London:

Geoffrey Cumberlege.) 195I. 45s.

Professor Sigerist has often placed the world of learning in his debt. He now enriches it with a volume, the first of a series of eight on the history of medicine, which is the outcome of 25 years of research and teaching. The gratitude of the medical profession and of all scholars is due not only to the author, but to Yale University and those individuals, trusts and foundations whose wisdom and generosity has made this great project possible.

- Professor Sigerist has approached his subject from an ecological standpoint, including in his field all that is understood by the term social medicine. His work provides a new basis for that concept; it may be hoped that it will also broaden the outlook of those medical historians whose method is genealogical and for whom the echoing corridors of time are straight avenues of progress, reassuringly patrolled by 'fathers' each with his discovery beside him. Professor Sigerist's field is global, his period limited only by the material available. He vindicates the claim made by Professor John Fulton in the preface: 'Dr. Sigerist is probably the only living scholar who has both the training and the vision to approach the development of medicine on this vast scale.' The volume covers primitive medicine and archaic medicine-Egyptian and Mesopotamian. From a study of material in museums and, more especially, of palaeopathological specimens, a comprehensive picture is given of periods and races for which no written records, or only limited ones, exist. In a style simple and intimate the author guides his readers effortlessly through the labyrinthine paths of folklore, magic and religion, explaining philosophical, theological and empirico-rational systems of medicine, drawing attention to the literature, art and music of long dead civilisations, and the social and economic structure of their societies. An attitude of scientific objectivity is maintained throughout. Such selfdiscipline might easily produce a colourless statement of fact, but the human interest is preserved by means of numerous quotations from contemporary sources. As befits a great teacher, Professor Sigerist is didactic; when cautious or speculative comments are made, they are a reminder of the extreme antiquity of the sources on which he has drawn, a fact which the reader easily forgets when confronted with descriptions so vivid. The book is fully illustrated, the collections of the Wellcome Historical Medical Museum being the source of many of the photographs. It is admirably.printed. The author gives copious references, notes, and selective bibliographies. This volume can be regarded as a valuable work of reference, but it is a great deal more than that: 'The picture we carry of our past is a powerful instrument of life ' (p. 30) and Professor Sigerist has through his researches given a new dignity to the profession of medicine.

\section{THE PHARMACOLOGY AND THERAPEUTICS̊} OF THE MATERIA MEDICA

By Walter J. Dilling, M.B., Ch.B., M.P.Sc (HoN.). rgth Edition. Pp. xxxii +598 ? London: Cassell \& Co. r95r. 2 rs.

This comprehensive book on the pharmaceutical, pharmacological and therapeutic aspects of drugs has reached its roth edition, but unfortunately its appearance has been delayed until after the death of its well-known author, Professor Walter J. Dilling. Much new material has been incorporated into this latest edition. This has meant, firstly, extensive revision to conform with the official preparations of the British Pharmacopoeia, 1948, and secondly, the addition of new sections on important new groups of drugs such as antibiotics and other chemotherapeutic remedies, Vitamin Br2, folic acid and intravenous iron in anaemias, cortisone and adrenocortico-tropic hormone in rheumatoid arthritis and muscular relaxants in anaesthesia. The attitude to pharmacology is perhaps old-fashioned, but the book is packed with information of value to students and practitioners of medicine.

C.A.K.

\section{MODERN TRENDS IN PAEDIATRICS}

Edited by the late Sir Leonard Parsons, M.D., F.R.S., F.R.C.P. Pp. $x+601$, with r ro illustrations. London: Butterworth \& Co. 195 I. $55 \mathrm{~s}$.

This is a book which cannot fail to be of interest to all postgraduates whose work touches on paediat- 